\title{
The Impact of Car-Sharing on the Willingness to Postpone a Car Purchase: A Case Study in Hangzhou, China
}

\author{
Ying Hui $(\mathbb{D}$, Yujiao Wang $(\mathbb{D}$, Qinlu Sun, and Lei Tang \\ Key Laboratory of Road and Traffic Engineering of the Ministry of Education, Tongji University, 4800 Caoan Road, \\ Shanghai 201804, China \\ Correspondence should be addressed to Ying Hui; 01022@tongji.edu.cn
}

Received 2 December 2018; Revised 4 April 2019; Accepted 22 April 2019; Published 2 May 2019

Academic Editor: Rocío de Oña

Copyright (C) 2019 Ying Hui et al. This is an open access article distributed under the Creative Commons Attribution License, which permits unrestricted use, distribution, and reproduction in any medium, provided the original work is properly cited.

\begin{abstract}
This paper aims to explore the potential of car-sharing in reducing car ownership and what are the impact factors. Based on the data of Hangzhou "Fun Car-sharing" system, a discrete choice model was established to study the willingness to postpone car purchase with participation in car-sharing. Compared with previous studies, this study included the variables involved in the questionnaire and those related to the usage characteristics extracted from rental data and GPS data. The questionnaire data indicate that about $50 \%$ of respondents will postpone car purchase by participating in car-sharing. The discrete choice model indicates that car-sharing in China can play a role in delaying car purchase. The results further suggest that respondents who use car-sharing more frequently, travel to work by car, or have an activity anchor in their trip are more likely to postpone car purchase. Moreover, respondents whose most common travel purpose of car-sharing is work-related or car purchase plan is definite are less likely to postpone car purchase after participating in car-sharing. The insights gained in this study can help cities and car-sharing operators to formulate relevant policies and regulation that optimally integrate car-sharing services into the overall urban transport systems.
\end{abstract}

\section{Introduction}

Recent years, car-sharing, as a relatively mature and popular trip mode which is between the private car and public transportation system, has gradually gained popularity. Compared with foreign countries, car-sharing started relatively late in China. The first large-scale car-sharing system was operated by Hangzhou EVnet Company. As a city with rapid development of Internet economy, people in Hangzhou are more willing to accept new things. As a result, many new industries are getting a head start in Hangzhou.

Most studies on car-sharing were performed in Europe and North America, and situations are likely different in China. Above all, the level of car ownership varies dramatically. In China, the majority of families did not have a car until recently. There are 36 cars per 100 households on average in China compared with 150-200 in Europe and North America. However, the ownership of private cars is growing at the rapid rate of $15 \%$. In addition, private car purchase is a very prudent decision for a Chinese family. Due to the difference in the process of private motorization, the impact of car-sharing on car ownership may vary in different countries. Additionally, debate remains as to whether car-sharing draws riders away from public transit systems, especially during peak hours. Car-sharing members may stimulate car purchase, as they experience the convenience of driving.

However, considering that car-sharing in China has just started, which is not widely used and most cities are still in rapid development of private motorization, the private car ownership level is not high. At the same time, the willingness to support cars is a will of the future, under the policy of the private car limit, the available transit system, the travel costs, etc. So that, in the aspect of owning a car, the actual effects will take a few years to show. It is difficult to assess the direct impact of car-sharing on the ownership of private cars. Therefore, we conducted a survey to only investigate the impact of car-sharing on the willingness of car purchase in China. The case we chose is a round-trip car-sharing scheme in Hangzhou named FunCarsharing. Different from some studies, we focused on car-sharing members rather than ordinary consumers. Additionally, the research results of rental data and GPS data were considered in the process of questionnaire survey and modelling. Thus, this comprehensive study on car-sharing combines 
three aspects of information to make the results more convincing.

Some members believe that car-sharing is a temporary or even a long-term substitute for private cars, especially as an alternative for second or third cars in a household. This is of great importance since a slowdown in private car growth provides valuable time for the development of public transport in the city, which would give travellers more travel options instead of relying on private cars. For the government, this strategy would ease pressure on the demand for private car ownership and satisfies desires for car use [1].

The remainder of this paper is organized as follows: "Literature Review" section provides a brief review on relevant literature; "Data Preparation" section describes survey design, data collection, and proceeds statistics analysis; "Method and Analysis" section introduces the model estimation; "Results and Discussion" section elaborates the results we obtained from multiple analyses. The final section summarizes the main conclusions and provides a discussion regarding the policy implication of the results. Among others, we discuss the implications of our results for the area of carsharing.

\section{Literature Review}

2.1. Car-Sharing. The car-sharing systems were introduced in the years '70-'80 [2]. Car-sharing systems have been extensively analyzed, evaluating both their impacts in a transport system and their determinants, i.e., which factors affect the choice to become a member and to use this service to complete a trip [3].

Studies on car-sharing members have mainly focused on the characteristics of members, including motivation and usage patterns. The people who are attracted to car-sharing projects may differ regionally. Studies in North America and Europe revealed that car-sharing members are relatively younger, are usually highly educated, and have lower car availability [4-6]. Wang et al. conducted a survey in Shanghai in 2011, when car-sharing was unfamiliar to most citizens. The result showed that younger people with fewer cars are more interested in car-sharing [7]. Another study in Beijing concluded that older people are more likely to use car-sharing for a given trip [8].

The choice motivation is analyzed by a discrete choice model and a structural equation model. Shaheen and Cohen identified cost savings, convenient locations, and guaranteed parking as the most common motivations for car-sharing use [9]. Tobias used a qualitative means-end chain analysis approach to identify four underlying motivational patterns: value-seeking, convenience, lifestyle, and environmental [10].

The studies on usage patterns have mostly been based on stated preference survey responses, but Hui et al. analyzed the spatial and temporal characteristics of car-sharing users in Hangzhou based on actual operational data [11, 12]. Those research results are also used in this analysis to enhance the reliability of the questionnaire. And in related works, carsharing was reported inducing members to decrease vehicle miles travelled $[13,14]$ and the number of trips per week [15] while increasing their attitudes to combine different transport modes such as bikes and walking $[6,16]$.

2.2. Car Ownership Impacts. The benefits of car-sharing have been reported in many previous studies. Here we focus on the impacts of car-sharing on car ownership. By providing occasional access to a personal car, car-sharing likely enables households to give up their private cars. Previous research focusing on the impact of car-sharing on car ownership mainly asked current users of car-sharing systems to report their (intentions of) ownership change after joining carsharing [13, 17-20].

Much tracking analysis on car-sharing has been carried out in North America. In San Francisco, Cervero et al. assessed the short-term, intermediate-term, and long-term impact of car-sharing on travel behavior and car ownership $[13,21,22]$. A binomial logit model was established to predict net changes in car ownership. Membership status has the largest impact on the odds of giving up car ownership, as expected. The results of a survey on the Arlington Pilot Carshare Program in 2005 indicated that car-sharing members were less likely to sell a currently owned car, but more likely to postpone a new car purchase [23]. A survey conducted among PhillyCarShare members in the Philadelphia region found that $7 \%$ of participants avoided car purchase and $25 \%$ got rid of their car as a result of their participation in the PhillyCarShare [24]. In 2004, Millard Ball et al. conducted a web-based survey of car-sharing members in the US and Canada. In total, $55.2 \%$ of the respondents agreed or strongly agreed that they were able to sell their car, the family's second car, or both [25]. Becker et al. compared two carsharing schemes in Switzerland and concluded $8 \%$ of freefloating car-sharing members and 19\% of the station-based car-sharing members would buy a car if the respective carsharing scheme did not exist [26]. Car-sharing is also believed to have a considerable effect on members' behavior in Lisbon, Portugal. Six months after the launching of a car-sharing system, $21 \%$ of the members started using transport modes other than cars, and 8\% no longer own a car [27].

Millard Ball et al. reviewed several European and North American studies from 1990 to 2005 and summarized the effect of car-sharing on car ownership. In 15 European studies, the average percentage of respondents who sold a car and gave up plans to purchase a car was both 22\%. In 15 North American studies, the average percentage of respondents who sold a car and gave up purchase of a car was $21 \%$ and $34 \%$, respectively [25].

Related studies in Asia have been performed only recently. Daejin Kim et al. conducted a survey in Seoul, Korea, implying car-sharing did not have an influential effect on car ownership behavior changes during the early stage of a car-sharing program [17]. The results of a study in Singapore showed that approximately $40 \%$ members joined a car-sharing program because public transport and carsharing together were adequate substitutes for private car ownership [1]. In China, Wang et al. conducted an online survey to measure the influence of car-sharing on private car reduction; $62.1 \%$ of participants were willing to give up buying new cars if car-sharing service could satisfy their 


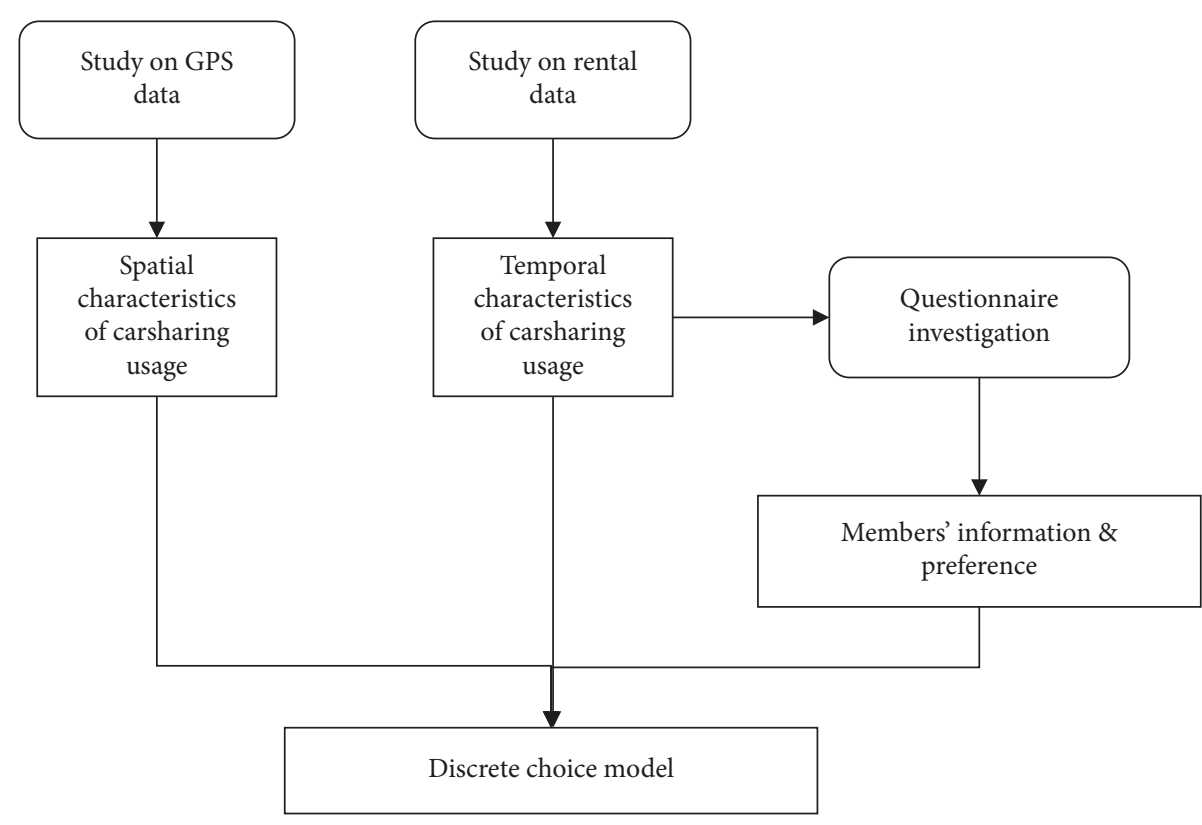

FIGURE 1: Data sources for modelling, including GPS data, rental data, and questionnaire data.

travel demand [28]. However, the surveyed people were not necessarily car-sharing members, or not even aware of carsharing.

While there is a considerable body of existing empirical research on the impacts of car-sharing, much of it has been conducted in developed countries. And most of the studies are merely based on questionnaire surveys, which cannot reveal the objective usage data or the impact of car-sharing usage on car ownership.

\section{Data Preparation}

The results of this paper are based on a questionnaire survey administered to members in "FunCarsharing", a round-trip car-sharing system in Hangzhou, China. One of the first carsharing platforms in China, FunCarsharing, was launched in 2010 and included more than 2000 members and 81 stations as of 2016. Previous studies of our team have analyzed the temporal and spatial characteristics of the usage patterns $[11,12]$.

The characteristics of car-sharing trips were analyzed according to the questionnaire data, rental data, and GPS data. The respondents of the questionnaire are members of FunCarsharing. The survey was conducted online from December 2016 to February 2017. In total, 648 completed questionnaires were received. The final number of effective questionnaire was 627 , after deleting some invalid submissions. And 31,446 rental records with the corresponding car GPS data from December 2013 to June 2015 were searched to match the 627 members. The data sources used in this paper are shown in Figure 1.

3.1. Rental Data. As mentioned earlier, the research results of rental data and GPS data are used in this paper. The study on rental data was based on the no-personal privacy information car rental data of the car-sharing operation system, from September 2013 to September 2014. According to the study, all members of FunCarsharing are catalogued into two types, high-frequency users and low-frequency users. High-frequency users are those who had used the system for more than three months and whose frequency of usage was more than once a month or those who had used the system for more than nine months and whose frequency of usage was more than 0.5 a month. The high-frequency users make up only $21 \%$ of the total members but contribute $66 \%$ of valid orders [12]. Most of the low-frequency users only use FunCarsharing for a short amount of time. The data frame of rental data is shown in Table 1.

According to the information provided by the rental data, the car-sharing use frequency of members corresponding to 627 valid questionnaires can be obtained, as shown in the Figure 2.

3.2. GPS Data. The GPS data ranged from December 2013 to June 2015, returned approximately every 30 s, regardless of whether it is moving or not. When the position coordinates of two consecutive GPS data are identical, the car is considered to stop within the time interval. The data frame of GPS data is shown in Table 2. And based on the unique order ID, the GPS data can be matched to obtain the travel track information of all the rental car $s$ of each member.

Referring to relevant research, if the stop time is longer than 720 s, then it is identified as an activity point, or more generally, a destination. The visiting frequency of every destination is used to depict the active anchor points of the members, which can be defined as the occurrence frequency of each destination relative to the total number of destinations of each member [11]. So that we have activity anchors, which means there are 1-3 frequently visited destinations. And 
TABLE 1: Data frame of rental data.

\begin{tabular}{lcc}
\hline Rental Data & & \\
\hline Column & Data type & Explanation \\
\hline ORDERID & CHAR & Identification of one rent process, unique \\
SERVICE STATION & VARCHAR & Position of service station that car was rented at \\
CARTYPE & VARCHAR & Different type of car has different charging standard \\
CARNUMBER & VARCHAR & License plate number of car \\
PHONE NUMBER & CHAR & Phone number of member \\
START_TIME & DATETIME & Time member picks the car \\
END_TIME & DATETIME & Time member returns the car \\
DRIVING DISTANCE & FLOAT & Distance of car movement \\
PAYMENT & FLOAT & The amount of money that member has paid \\
RADIUS & FLOAT & The maximal distance between every single data point and service station \\
DURATION & DATETIME & The duration time of rental \\
ACTIVE MEMBER & INT & $1=$ “active member"; 0= “inactive member" \\
\hline
\end{tabular}

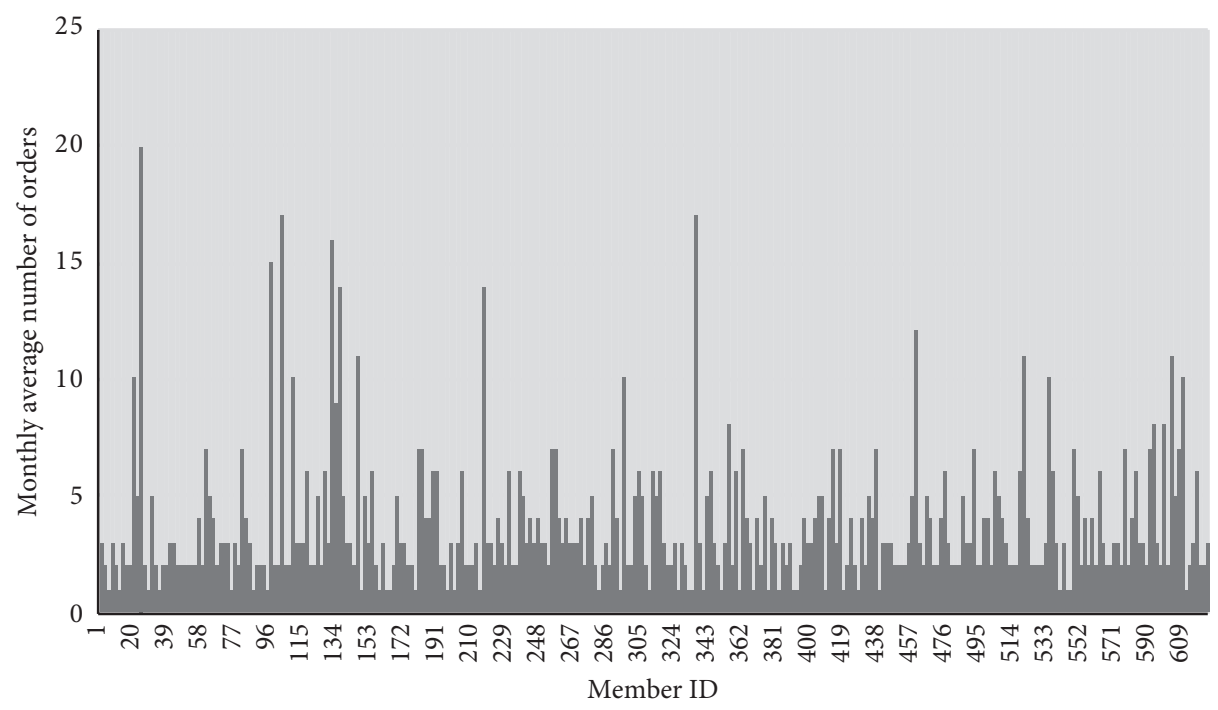

FIGURE 2: Use frequency of 627 members.

$54.4 \%$ of the members have one activity anchor, shown in Table 3.

3.3. Questionnaire Data. The questionnaire consisted of four parts: demographic characteristics, traffic mode, car-sharing usage, and the impact of car-sharing on car ownership.

3.3.1. Sociodemographics. The gender and age of members were provided by FunCarsharing, with 56 records missing for gender and 63 missing for age. Among the respondents, men were represented significantly more than women, accounting for $89 \%$ of the total number. Members between 25-34 years old accounted for $75.6 \%$ of respondents. Males of young age were substantially overrepresented among car-sharing members in FunCarsharing.

Table 4 shows the sociodemographics of respondents. Nuclear families of 1-3 adults accounted for 48\%. Except for a few families with only one person, there was little difference in the proportion of households with 2-4 people or more than 5 people. The clear majority of unmarried members still classify themselves as native families with their elders, according to traditional family values.

In the survey results, $67 \%$ of the respondents have at least one car in their households, which was well above that of previous studies in Europe and America. This is also different from the expected results before the survey. Those who own cars and have more than one-year driving experience account for $53.3 \%$ of the members surveyed. For those who have cars in their home, $49 \%$ drive more than 4 days per week. Thus, it can be inferred that members living in a household with cars have a stronger dependence on individual motorized travel. Members are generally well-educated, as $72 \%$ of the respondents have a college degree or above.

There is a significant correlation between car ownership and the commuting mode choice. The proportion of members commuting by car in car-owning households (49\%) is much higher than that from car-free households (8\%), and the proportion of members commuting by public transit in car-owning households (25\%) is far lower than that from carfree households (47\%). 
TABLE 2: Data frame of GPS data.

\begin{tabular}{lcc}
\hline GPS Data & & \\
\hline Column & Data type & Explanation \\
\hline ORDERID & CHAR & Identification of one rent process, unique \\
CARNUMBER & VARCHAR & License plate number of car \\
ADD_TIME & DATETIME & Return time of data \\
LONGITUDE & FLOAT & Longitude of car position \\
LATITUDE & FLOAT & Latitude of car position \\
\hline
\end{tabular}

TABLE 3: Activity anchor of the members.

\begin{tabular}{lcc}
\hline Anchor & One activity anchor & Otherwise \\
\hline Percentage[\%] & 54.4 & 45.6 \\
\hline
\end{tabular}

3.3.2. Usage Patterns. Understanding the purpose of carsharing rides is a concern of enterprises as well as governments and is a key component of determining the orientation of the car-sharing market. Different car-sharing modes would be expected to serve different markets. As illustrated in Table 5, the car-sharing service was employed for multiple purposes. Only $20 \%$ of the respondents state that the main purpose of their car-sharing rides is commuting, which is uneconomical for round-trip car-sharing since it usually takes more than 8 hours to return the car to the same station. It is the result of the preferential pricing for night usage. In this usage pattern, members often rented a car at dusk and returned it the next morning. Usually, they used car-sharing for multiple purposes and not just for commuting.

To better understand what kinds of transportation are alternatives to car-sharing, respondents were asked what they would do if car-sharing was not available. Table 6 shows the results. Only $24.7 \%$ of trips were replaced by urban transit, and $86.6 \%$ of respondents indicated that they would still drive or ride a car. This indicates that round-trip car-sharing mostly serves indispensable trips requiring a car. In other words, carsharing is unlikely to increase MVT or draw riders away from a public transit system.

3.3.3. Attitude and Satisfaction. Multiple questions were designed in the questionnaire to examine the attitudes of car-sharing program members towards car ownership after they participated in the car-sharing scheme. They were asked to state their agreement on a 5-point Likert Scale. As illustrated in Table 7, most respondents regard car-sharing as a temporarily substitute for family cars, especially as a substitute for a second car in the household. There are a small number of people who intend to use car-sharing for a long time and forgo buying another car. Based on this, we analyzed the impact of car-sharing on car ownership.

According to the survey of member satisfaction, more than half of the members are satisfied with the overall situation of car-sharing (61\% of all sample members), while compared with the service quality of car-sharing, most members are not satisfied with their expenses. As for the convenience and cleanliness of the car, the satisfaction is higher. The specific satisfactions are shown in Table 8.

\section{Method and Analysis}

To assess the impact of car-sharing on car ownership, participants were asked whether their car purchase plan changed after participating in car-sharing. Members could answer ahead of plan, no effect, postpone, give up temporarily, or give up permanently. The percentage of members choosing different options is shown in Table 9, and the responses varied greatly. We merged them into two classes, postpone car purchase (including giving up temporarily and permanently) or no postponement (ahead of plan or no effect).

We next built a binominal logit regression to analyze factors that influence the willingness of postponing car purchase. To accommodate the binominal logit model, the response variable CAR_POSTPONE was created, containing 1 if respondents state they will postpone buying a car and 0 otherwise.

The general form for the binominal logit model used in this work is shown in below:

$$
P=\frac{e^{\beta}}{1+e^{\beta}}, \quad \beta=\beta_{0}+\beta_{1} x_{1}+\cdots+\beta_{k} x_{k}
$$

where $\mathrm{P}$ is the probability of respondent $\mathrm{n}$ to postpone car purchase and $\beta$ is the coefficient of the predictor variables. In addition to variables obtained in the questionnaire, alternative variables were used, including CS_FREQ from the study on rental data and ANCHOR from the study on GPS data [11, 12]. CS_FREQ means the average times members use car-sharing services on a monthly basis. ANCHOR is a nominal variable, of which the value equals 1 if the respondent has an activity anchor and 0 otherwise. The following is the definition of activity anchor. We divide the members into two categories. Members of the first category have activity anchors; members of the second category do not have activity anchors. In this case, the members either did not have frequent particular destinations or used the car-sharing service too infrequently to determine an activity anchor.

The significance of model parameters was tested at the 5\% level of significance. SPSS was used to fit the regression. Tables 10 and 11 display the information of significant variables in the model.

As illustrated in Table 12, we found the factors that affect car-sharing members in postponing a car purchase. Some of them are quite logical, while others were rarely mentioned in previous studies.

Above all, no social-demographic attributes were included in the model. This might be because car-sharing in the early stage attracts a particular set of consumers with 
TABLE 4: Sociodemographics of members that were surveyed.

\begin{tabular}{|c|c|c|c|}
\hline Characteristics & & Frequency & Percentage[\%] \\
\hline \multirow{3}{*}{ Marriage and kids } & Married with kids & 260 & 41.5 \\
\hline & Married with no kids & 93 & 14.8 \\
\hline & unmarried & 265 & 42.3 \\
\hline \multirow{5}{*}{ Adults in household } & 1 person & 5 & 0.8 \\
\hline & 2 persons & 142 & 22.6 \\
\hline & 3 persons & 158 & 25.2 \\
\hline & 4 persons & 186 & 29.7 \\
\hline & $\geq 5$ persons & 136 & 21.7 \\
\hline \multirow{3}{*}{ Driving experience } & More than 3 years & 261 & 41.6 \\
\hline & 1-3 years & 182 & 29.0 \\
\hline & Less than 1 year & 184 & 29.3 \\
\hline \multirow{3}{*}{ Degree } & High school & 175 & 27.9 \\
\hline & College & 396 & 63.2 \\
\hline & Graduate or above & 56 & 8.9 \\
\hline \multirow{4}{*}{$\begin{array}{l}\text { Family annual income } \\
\text { (¥) }\end{array}$} & Less than 100,000 & 316 & 50.4 \\
\hline & $100,000-200,000$ & 173 & 27.6 \\
\hline & $200,000-300,000$ & 85 & 13.6 \\
\hline & More than 300,000 & 53 & 8.5 \\
\hline \multirow{2}{*}{$\begin{array}{l}\text { Walk time to the } \\
\text { nearest bus station }\end{array}$} & $\leq 15$ minutes & 449 & 71.6 \\
\hline & $>15$ minutes & 178 & 28.4 \\
\hline \multirow{5}{*}{$\begin{array}{l}\text { Commuting traffic } \\
\text { mode }\end{array}$} & Drive or ride a car & 228 & 36.4 \\
\hline & Transit & 201 & 32.1 \\
\hline & Taxi & 16 & 2.6 \\
\hline & Bike or walk & 159 & 25.4 \\
\hline & Others & 23 & 3.7 \\
\hline \multirow{4}{*}{$\begin{array}{l}\text { Household car } \\
\text { ownership }\end{array}$} & 0 car & 200 & 31.9 \\
\hline & 1 cars & 323 & 51.5 \\
\hline & 2 cars & 92 & 14.7 \\
\hline & $\geq 3$ cars & 12 & 1.9 \\
\hline
\end{tabular}

TABLE 5: Main trip purpose of car-sharing rides.

\begin{tabular}{lcccccccc}
\hline Purpose & Commute & $\begin{array}{c}\text { Business and } \\
\text { errands }\end{array}$ & Visit & Escort sb. & Shopping & Leisure & Jaunt & $\begin{array}{c}\text { Goods } \\
\text { Transport }\end{array}$ \\
\hline Percentage[\%] & 20.0 & 17.3 & 13.3 & 9.9 & 5.5 & 15.7 & 15.0 & 3.2 \\
\hline
\end{tabular}

similar characteristics. On the other hand, it shows that the willingness to postpone car purchase is more closely related to car-sharing usage characteristics rather than the personal traits of members.

Those who are more cost conscious or more satisfied with car-sharing are more inclined to postpone a car purchase, which makes sense. Car-sharing is an alternative of private car ownership, offering convenience at a relatively low cost, and these people will be more inclined to postpone car purchase. If members have better experience of car-sharing, it is more likely to become a satisfactory transportation option and may replace a private car.

In addition to the factors mentioned above, respondents with the following attributes are more likely to postpone car purchase after participating in car-sharing.
4.1. Use Car-Sharing More Frequently. The frequency of carsharing usage was verified by objective data, which was more reliable than the questionnaire results. The model result implies that the cumulation of car-sharing experience will affect the trend of ownership to some extent. From this perspective, if car-sharing does induce some car travel, this part of car travel will be delayed by the postponement of car purchase because car travel will significantly increase after the purchase of private cars. Substantial previous research suggested that car-sharing members tend to decrease their use of cars. Estimates of the degree to which households reduce their VMT vary from $27 \%$ to $68 \%$ [13, 29-31].

4.2. Travel to Work by Car. Previous studies focused more on car ownership in households, but less on respondents' 
TABLE 6: Reaction of members when car-sharing was not available.

\begin{tabular}{lccccrc}
\hline Alternative & $\begin{array}{c}\text { Used another } \\
\text { car }\end{array}$ & Took a taxi & $\begin{array}{c}\text { Used public } \\
\text { transport }\end{array}$ & Carpooled & $\begin{array}{c}\text { Cancelled the } \\
\text { trip }\end{array}$ & Other \\
\hline Percentage[\%] & 32.1 & 21.7 & 24.7 & 19.8 & 1.1 & 0.6 \\
\hline
\end{tabular}

TABLE 7: Responses to attitudinal questions.

\begin{tabular}{|c|c|c|c|c|}
\hline \multicolumn{5}{|c|}{ Car-sharing is temporarily used, but not a long-term substitute for family cars. } \\
\hline Completely disagree[\%] & Disagree[\%] & Uncertain[\%] & Agree[\%] & Completely agree[\%] \\
\hline 3.2 & 7.0 & 19.8 & 48.6 & 21.4 \\
\hline \multicolumn{5}{|c|}{ I do not intend to buy a car, considering long-term use of car-sharing. } \\
\hline Completely disagree[\%] & Disagree[\%] & Uncertain[\%] & Agree[\%] & Completely agree[\%] \\
\hline 8.8 & 28.8 & 31.3 & 26.8 & 4.3 \\
\hline \multicolumn{5}{|c|}{ Car-sharing can replace the second car in the household. } \\
\hline Completely disagree[\%] & Disagree[\%] & Uncertain[\%] & Agree[\%] & Completely agree[\%] \\
\hline 2.0 & 11.7 & 30.9 & 43.0 & 12.4 \\
\hline
\end{tabular}

TABLE 8: Responses to satisfaction questions.

\begin{tabular}{lccccccc}
\hline Aspects & $\begin{array}{c}\text { Accident } \\
\text { compensation }\end{array}$ & Cost & $\begin{array}{c}\text { Easy access to } \\
\text { outlets }\end{array}$ & $\begin{array}{c}\text { Convenience of } \\
\text { getting and } \\
\text { returning cars }\end{array}$ & $\begin{array}{c}\text { Cleanliness of } \\
\text { car }\end{array}$ & $\begin{array}{c}\text { Car type } \\
\text { satisfaction }\end{array}$ \\
\hline Very dissatisfied[\%] & 2.1 & 2.6 & 4.0 & 3.2 & 3.7 & 5.0 & 1.9 \\
Dissatisfied[\%] & 14.2 & 15.8 & 10.2 & 5.1 & 4.6 & 6.9 & 4.3 \\
General[\%] & 32.3 & 59.8 & 42.1 & 29.3 & 30.1 & 32.0 & 33.1 \\
Satisfied[\%] & 35.2 & 14.1 & 31.4 & 43.8 & 47.0 & 42.5 & 46.1 \\
Very satisfied[\%] & 16.2 & 7.7 & 12.3 & 18.6 & 14.6 & 13.6 & 14.6 \\
\hline
\end{tabular}

commuting mode choice. Some members are not the main drivers of owned cars. On the other hand, for respondents who commute by car, car-sharing is a complement to daily travel. Under this circumstance, car-sharing is a promising substitute for the second or third car in the household. Another study also indicated that car-sharing is not a reasonable option for every traveller. Car-sharing membership is more appealing for those who travel fewer kilometres and reside in higher-density neighbourhoods with good walking, cycling, and transit options [32]. Thus some car-sharing operators are targeting second car owners rather than car-free households as the market matures beyond the early adopters [25].

4.3. Have an Activity Anchor in Their Trip. Activity anchor is an original idea of car-sharing research, which reflects the different usage patterns of car-sharing among different members. Respondents with travel anchors, i.e., respondents with relatively frequent destinations, are more likely to postpone car purchase, because these members usually use car-sharing to take specific trips. It can be inferred that carsharing has distinct advantages over other transportation mode for these kinds of trips.

Respondents with the following attributes are less likely to postpone car purchase after participate in car-sharing.

4.4. The Most Common Travel Purpose of Car-Sharing Is WorkRelated. Work-related trips typically have relatively rigid demands, with higher requirements for time and reliability. Car-sharing is not accessible anywhere at any time and has a limited driving range. Additionally, public transit often is insufficient to meet the needs of some work-related trips, so these members are less likely to postpone car purchase. Although they are less likely to put off buying a car, according to members' self-evaluation, the frequency of car usage has declined significantly. That is to say, car-sharing is difficult to replace private cars in their minds. But in practice, they did reduce VMT because of car-sharing.

4.5. Car Purchase Plan Is Definite. Respondents who have a specific car purchase plan (if they determined to buy or not to buy a car in the next few years) are less likely to postpone car purchase. However, those who are deciding between two choices tend to be more influenced by carsharing, resulting in an increased propensity to change their plans. Car restriction policies have been enacted in several major cities in China, including Hangzhou City. Owning cars will cost more than ever and traffic congestion in the downtown is increasingly restricted to commuting by car. These conditions favor the development of car-sharing, since many people hesitate to decide if buying a car is a smart decision.

\section{Results and Discussion}

This paper combines questionnaire survey data with rental data and GPS data to study the impact of car-sharing on the 
TABLE 9: Change of car purchase plan after joining car-sharing.

\begin{tabular}{lccccc}
\hline Option & $\begin{array}{c}\text { Ahead of } \\
\text { plan }\end{array}$ & No effect & Postpone & $\begin{array}{c}\text { Give up } \\
\text { temporarily }\end{array}$ & $\begin{array}{c}\text { Give up } \\
\text { permanently }\end{array}$ \\
\hline Percentage[\%] & 5.6 & 45.0 & 28.9 & 15.8 & \\
\hline
\end{tabular}

TABLE 10: Descriptions of significant variables in the binominal logit model.

\begin{tabular}{lll}
\hline Variable & Measure & Description \\
\hline JOIN_ECO & Nominal & 1 if the respondent joins car-sharing mainly for economic reasons; 0 otherwise \\
CS_SATISFY & Ordinal & Respondent's level of satisfaction toward car-sharing \\
CS_FREQ & Nominal & Respondent's frequency of car-sharing use (times per month) \\
CAR_COMMUTE & Nominal & 1 if the respondent commutes by car; 0 otherwise \\
CS_PURPOSE & Nominal & 1 if the main purpose of trip by car-sharing is work-related; 0 otherwise \\
ANCHOR & Nominal & 1 if the respondent has an activity anchor; 0 otherwise \\
PLAN & Nominal & 1 if the respondent are very sure about car plan; 0 otherwise \\
\hline
\end{tabular}

TABLE 11: Descriptive statistics of significant variables.

\begin{tabular}{lccc}
\hline Variable & & Frequency & Percentage[\%] \\
\hline JOIN_ECO & 1 & 346 & 55.2 \\
& 0 & 281 & 44.8 \\
\hline & 1 & 12 & 1.9 \\
CS_SATISFY & 2 & 27 & 4.3 \\
& 3 & 209 & 33.3 \\
& 4 & 288 & 45.9 \\
& 5 & 91 & 14.5 \\
CS_FREQ & $1-2$ & 381 & 60.8 \\
& $3-4$ & 155 & 24.7 \\
\hline CAR_COMMUTE & $5-6$ & 51 & 8.1 \\
& $\geq 7$ & 40 & 6.4 \\
CS_PURPOSE & 1 & 245 & 39.1 \\
& 0 & 382 & 60.9 \\
ANCHOR & 1 & 218 & 34.8 \\
\hline \multirow{2}{*}{ PLAN } & 0 & 409 & 65.2 \\
\hline
\end{tabular}

TABLE 12: The result of binominal logit model.

\begin{tabular}{|c|c|c|c|c|c|c|}
\hline Variable & $\mathrm{B}$ & S.E. & Wald & $\mathrm{df}$ & Sig. & $\exp (B)$ \\
\hline JOIN_ECO & 0.340 & 0.172 & 3.909 & 1 & 0.048 & 1.405 \\
\hline CS_SATISFY & 0.386 & 0.104 & 13.883 & 1 & 0.000 & 1.471 \\
\hline CS_FREQ & 0.103 & 0.040 & 6.482 & 1 & 0.011 & 1.108 \\
\hline CAR_COMMUTE & 0.421 & 0.175 & 5.785 & 1 & 0.016 & 1.523 \\
\hline CS_PURPOSE & -0.464 & 0.180 & 6.609 & 1 & 0.010 & 0.629 \\
\hline ANCHOR & 0.570 & 0.171 & 11.139 & 1 & 0.001 & 1.768 \\
\hline PLAN & -0.415 & 0.192 & 4.677 & 1 & 0.031 & 0.660 \\
\hline Constant & -1.935 & 0.467 & 17.164 & 1 & 0.000 & 0.144 \\
\hline Chi-square(7 d.f.) & \multicolumn{6}{|c|}{58.064} \\
\hline Significance level & \multicolumn{6}{|c|}{0.000} \\
\hline$-2 \log$ likelihood & \multicolumn{6}{|c|}{811.064} \\
\hline Nagelkerke's R Square & \multicolumn{6}{|c|}{0.118} \\
\hline
\end{tabular}


willingness of car ownership of members, which improves the credibility of variables, and also reflects the influence of usage behavior on car purchase plan. From rental data, we get usage frequency of members, which can truly reflect the use of carsharing. And from GPS data, we can analyze members' usage patterns objectively. And in-depth analysis of these two parts of data has been carried out in other papers.

The results indicate that car-sharing in China can play a role in delaying the purchase of cars. And the use frequency will make a difference, which has two side effects for private car use and road pressure; especially under the background of capital intervention and enterprise marketing, how to avoid car-sharing becomes the transition of owning a car which still needs further investigation. However, in China, few researches focused on the impact of car-sharing on car ownership; the relevant conclusions obtained in this paper can fill the gap.

Our study found that $49.4 \%$ of the respondents state that they will postpone or give up buying a car because of carsharing. Although this amount is lower than that of developed countries, it is still encouraging. The slowdown in private car growth provides valuable time for the development of urban transit and the formulation of an effective management strategy of cars. Moreover, the frequency and the mode of car-sharing use have a significant impact on postponing car purchase. Members tend to change their plans of car purchase only when they form relative regular usage patterns. Thus, the government should support the development of car-sharing to some extent.

5.1. Control Outlet Density and Different Point Pickup and Return Mode. The outlets should be added appropriately in tourist attractions and the areas where jobs are concentrated. At the same time, the density should be strictly restricted to control the use of car-sharing at a moderate level. And the appropriate development of the mode that allows members to pick up and return cars at different points is necessary to improve the degree of convenience of car-sharing.

5.2. Control Cost. It is suggested to increase the cost of car purchase appropriately. For the usage cost of car-sharing, it is suggested to put an end to the phenomenon of low-price promotion and control it lower than the usage cost of private cars. A low-price competition between enterprises will lead to a great increase in car-sharing use, which will aggravate the urban traffic burden. In addition, the use of car-sharing can also be given a certain discount, which should be limited during rush hours.

5.3. Optimize Car-Sharing Services. As previously mentioned, satisfaction can affect the willingness of delaying the purchase of another car. Those who are more satisfied with car-sharing are more inclined to postpone a car purchase. In addition to the cost and convenience of getting and returning cars, the accident compensation, cleanliness of car, and car type are also crucial to the overall satisfaction.

So it is suggested to provide more car types for members to choose and regularly clean the cars. In addition, in order to meet the requirements of car-sharing service for different travel purposes of members, it is suggested to provide some personalized services, such as child seats and navigation systems.

\section{Conclusions}

In this paper, we built a binominal logit model to analyze the impact of car-sharing on the willingness to postpone a car purchase, based on the GPS data, rental data, and questionnaire data of Hangzhou "Fun Car-sharing" system. The results showed that the willingness to postpone car purchasing is associated with the motivation to join carsharing, satisfaction of using car-sharing, frequency of carsharing usage, the purpose of trip, travel characteristics, and whether the car purchase plan is definite. We conclude that car-sharing has a positive impact on delaying the private car purchasing in China, especially the frequency and the mode of car-sharing use.

However, we should also be aware of some disadvantages of car-sharing. Car-sharing programs of different scales have started in big cities in China. Extreme competition among programs in the same area should be avoided, since the fee is a main concern of many members, for motivation to start or willingness to continue using. The outlet density should not be too intensive, to control the use of car-sharing at a moderate level.

For car-sharing enterprises, this data can help to improve service and the satisfaction of members. Satisfaction is closely associated with the willingness of delaying the purchase of another car. When members postpone buying cars, they are expected to use car-sharing services for longer time. In addition, we advise that more reliable and high-quality cars be launched in business districts to attract an increased number of work-related trips.

In this research, all the analysis is based on members of Hangzhou "Fun Car-sharing" system. However, under the car-sharing mode which members can only pick up and drop off the car at the same place, members' usage features may not be applicable to other car-sharing modes such as car returning at different points or drift type. Analysis results may have limitations. In addition, the quantitative analysis of car purchase plan in this paper lacks objective data tracking survey, and the research results have certain deviation.

In the future research, the data of members under different car-sharing modes should be collected for comprehensive analysis. In addition, the comprehensive influence of driving cost and maintenance cost on members' car purchase behavior should also be considered.

This research contributes to efforts to pinpoint the orientation of car-sharing and can guide the operation of carsharing enterprises and the formulation of relevant policies and regulation. The conclusion can help us to provide scientific basis for service improvement and provide a basis for policy making.

\section{Data Availability}

The data used to support the findings of this study are available from the corresponding author upon request. 


\section{Disclosure}

And the earlier version of this paper has been presented as conference in Transportation Research Board 97th Annual Meeting, which can be found in the following link: https:// trid.trb.org/view/1496111.

\section{Conflicts of Interest}

The authors declare that they have no conflicts of interest.

\section{Acknowledgments}

This work was supported by the National nature science foundation of China [grant number 51408430].

\section{References}

[1] F. Tuan Seik, "Vehicle ownership restraints and car sharing in Singapore," Habitat International, vol. 24, no. 1, pp. 75-90, 2000.

[2] S. Shaheen, D. Sperling, and C. Wagner, Car-Sharing in Europe and North American: Past, Present, And Future, University of California Transportation Center, 2001.

[3] C. Riccardo and D. Marco, "Substitution and complementarity patterns between traditional transport means and car sharing: a person and trip level analysis," Transportation, pp. 1-18, 2018.

[4] J. Burkhardt and A. Millard-Ball, "Who is attracted to carsharing?” Transportation Research Record, vol. 1986, pp. 98-105, 2006.

[5] S. Tai, P. L. Mokhtarian et al., "Car-sharing and the Built Environment: a GIS-based study of one U.S operator," Institute of Transportation Studies Working Paper, vol. 11, 2008.

[6] J. Kopp, R. Gerike, and K. W. Axhausen, "Do sharing people behave differently? An empirical evaluation of the distinctive mobility patterns of free-floating car-sharing members," Transportation, vol. 42, no. 3, pp. 449-469, 2015.

[7] M. Wang, E. W. Martin, and S. A. Shaheen, "Carsharing in Shanghai, China," Transportation Research Record, vol. 2319, no. 1, pp. 86-95, 2012.

[8] T. Yoon, C. R. Cherry et al., "One-way and round-trip carsharing: a stated preference experiment in Beijing," Transportation Research Part D Transport \& Environment, vol. 53, pp. 102114, 2017.

[9] S. Shaheen, Cohen. et al., Growth in Worldwide Car-Sharing: An International Comparison, 2007.

[10] T. Schaefers, "Exploring car-sharing usage motives: a hierarchical means-end chain analysis," Transportation Research Part A Policy \& Practice, vol. 47, pp. 69-77, 2013.

[11] Y. Hui, M. Ding, K. Zheng, and D. Lou, "Observing trip chain characteristics of round-trip carsharing users in China: a case study based on GPS data in Hangzhou city," Sustainability, vol. 9, no. 6, p. 949, 2017.

[12] Y. Hui, W. Wang, M. Ding, and Y. Liu, "Behavior patterns of long-term car-sharing users in China," Transportation Research Procedia, vol. 25, pp. 4666-4682, 2017.

[13] R. Cervero, A. Golub, and B. Nee, "City CarShare longerterm travel demand and car ownership impacts," Transportation Research Record, no. 1992, pp. 70-80, 2007.

[14] E. Martin and S. Shaheen, Impacts of Car2go on Vehicle Ownership, Modal Shift, Vehicle Miles Travelled, and Greenhouse Gas Emissions: An Analysis of Five North American Cities, 2016.
[15] B. Zhou and K. M. Kockelman, "Opportunities for and impacts of carsharing: a survey of the Austin, Texas market," International Journal of Sustainable Transportation, vol. 5, no. 3, pp. 135-152, 2011.

[16] R. R. Clewlow, "Carsharing and sustainable travel behavior: results from the San Francisco bay area," Transport Policy, vol. 51, pp. 158-164, 2016.

[17] D. Kim, J. Ko, and Y. Park, "Factors affecting electric vehicle sharing program participants' attitudes about car ownership and program participation," Transportation Research Part D: Transport and Environment, vol. 36, pp. 96-106, 2015.

[18] J. Firnkorn and M. Müller, "What will be the environmental effects of new free-floating car-sharing systems? The case of car2go in Ulm," Ecological Economics, vol. 70, no. 8, pp. 15191528, 2011.

[19] J. Firnkorn and M. Müller, "Free-floating electric carsharingfleets in smart cities: The dawning of a post-private car era in urban environments?" Environmental Science \& Policy, vol. 45, pp. 30-40, 2015.

[20] G. S. Mishra, R. R. Clewlow, P. L. Mokhtarian, and K. F. Widaman, "The effect of carsharing on vehicle holdings and travel behavior: a propensity score and causal mediation analysis of the San Francisco bay area," Research in Transportation Economics, vol. 52, pp. 46-55, 2015.

[21] R. Cervero, N. Creedman, M. Pohan, and M. Pai, City Car-Share: Assessment of Intermediate-Term Travel-Behaviour Impacts, University of California, 2002.

[22] R. Cervero and Y. Tsai, "City CarShare in San Francisco, California second-year travel demand and car ownership impacts," Transportation Research Record, no. 1887, pp. 117-127, 2004.

[23] Arlington Department of Environmental Services, "2005 Arlington Pilot Car-share Program First-Year Report," Tech. Rep., Arlington, VA, USA, 2005.

[24] PhillyCarShare by Econsult Corporation, The Economic and Environmental Impact of PhillyCarShare in the Philadelphia Region, Philadelphia, PA, USA, 2010.

[25] A. Millard-Ball, G. Murray, J. T. Schure et al., "Car-sharing: where and how it succeeds," Tech. Rep., Transportation Research Board of the National Academies, 2005.

[26] H. Becker, F. Ciari, and K. W. Axhausen, "Comparing carsharing schemes in Switzerland: User groups and usage patterns," Transportation Research Part A: Policy and Practice, vol. 97, pp. 17-29, 2017.

[27] P. Baptista, S. Melo, and C. Rolim, "Energy, environmental and mobility impacts of car-sharing systems. empirical results from lisbon, portugal," Procedia - Social and Behavioral Sciences, vol. 111, pp. 28-37, 2014.

[28] Y. Wang, X Yan, Y. Zhou et al., "Individuals' acceptance to free-floating electric car-sharing mode: a web-based survey in China," International Journal of Environmental Research \& Public Health, vol. 14, p. 476, 2017.

[29] E. Martin, Shaheen et al., The Impact of Car-Sharing on Household Vehicle Ownership, vol. 38, University of California Transportation Center Working Papers, 2011.

[30] L. Sioui, C. Morency, and M. Trépanier, "How carsharing affects the travel behavior of households: a case study of Montréal, Canada," International Journal of Sustainable Transportation, vol. 7, no. 1, pp. 52-69, 2012.

[31] D. Sperling, Shaheen et al., "Carsharing: niche market or new pathway?” Kfb Rapport, 1999. 
[32] T. D. Chen and K. M. Kockelman, "Carsharing's life-cycle impacts on energy use and greenhouse gas emissions," Transportation Research Part D: Transport and Environment, vol. 47, pp. 276-284, 2016. 


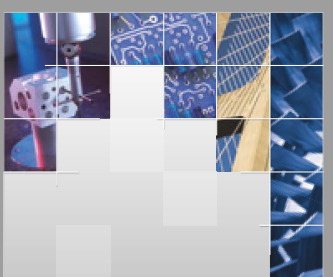

\section{Enfincering}
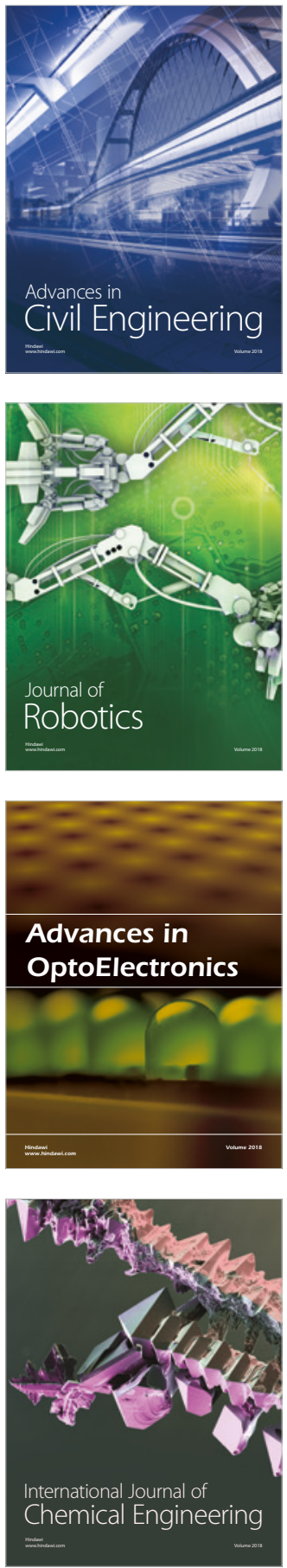

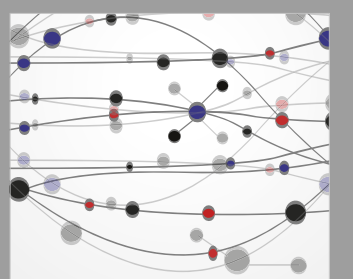

\section{Rotating \\ Machinery}

The Scientific World Journal

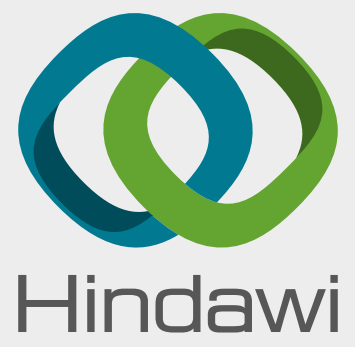

Submit your manuscripts at

www.hindawi.com
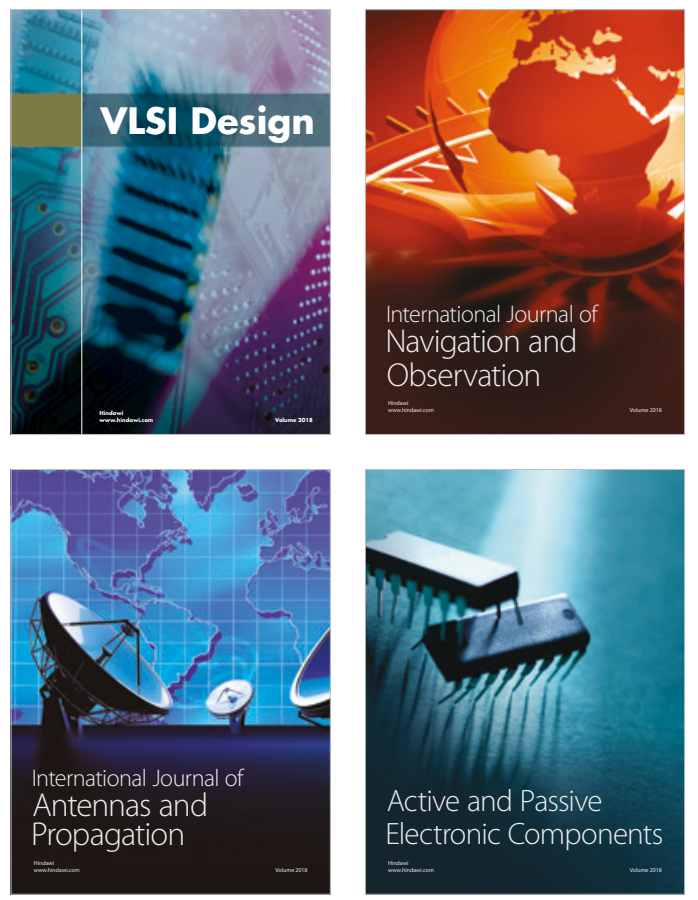
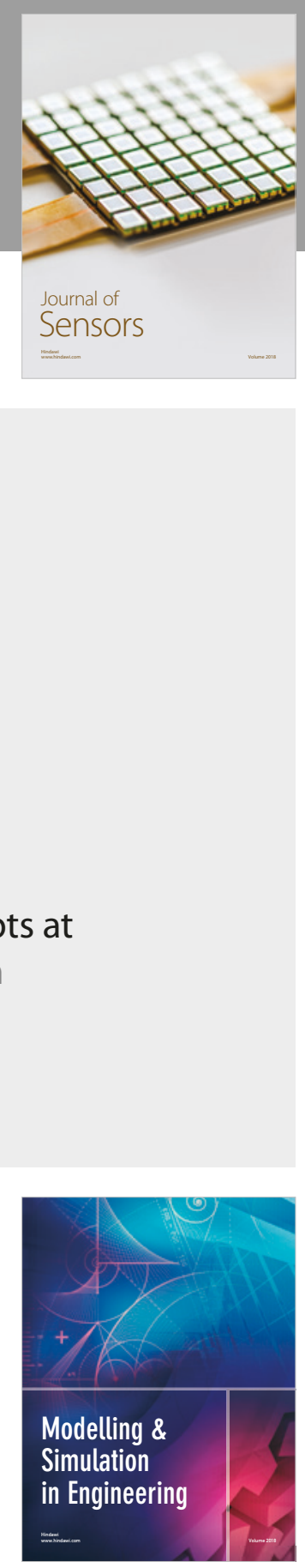

\section{Advances \\ Multimedia}
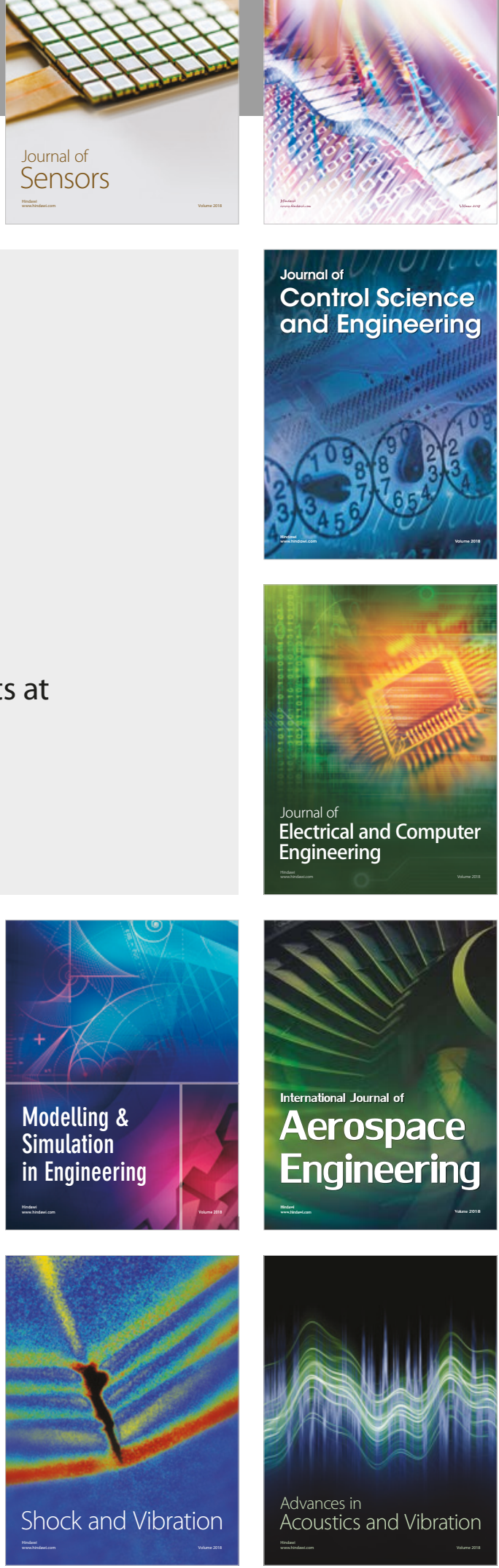